\title{
Large-scale association study between two coding LRP5 gene polymorphisms and bone phenotypes and fractures in men
}

\author{
E. Grundberg • E. M. Lau • M. Lorentzon • \\ M. Karlsson • A. Holmberg • L. Groop • D. Mellström • \\ E. Orwoll • H. Mallmin • C. Ohlsson • Ö. Ljunggren • \\ K. Åkesson
}

Published online: 7 August 2008

(C) International Osteoporosis Foundation and National Osteoporosis Foundation 2008

Erratum to: Osteoporos Int

DOI 10.1007/s00198-007-0512-x

The name of the third author was misspelt. His correct name is Mattias Lorentzon.

The online version of the original article can be found at http://dx.doi. org/10.1007/s00198-007-0512-z.

E. Grundberg $(\bowtie) \cdot$ Ö. Ljunggren

Department of Medical Sciences, Uppsala University Hospital,

75185 Uppsala, Sweden

e-mail: Elin.Grundberg@medsci.uu.se

E. M. Lau

Hong Kong Orthopedic and Osteoporosis,

Center for Treatment and research,

Hong Kong, China

M. Lorentzon · D. Mellström · C. Ohlsson

Center for Bone Research at the Sahlgrenska Academy,

Department of Internal Medicine, Göteborg University,

Gothenburg, Sweden

M. Karlsson · A. Holmberg · K. Åkesson

Clinical and Molecular Osteoporosis Research Unit,

Department of Clinical Science, Lund University,

Malmö, Sweden
M. Karlsson · A. Holmberg $\cdot$ K. Åkesson

Department of Orthopaedics, Malmö University Hospital, Malmö, Sweden

L. Groop

Department of Clinical Sciences, Diabetes and Endocrinology, Clinical Research Center, Malmö University Hospital,

Lund University,

Malmö, Sweden

E. Orwoll

Bone and Mineral Research Unit,

Oregon Health and Science University,

Portland, OR, USA

H. Mallmin

Department of Surgical Sciences, Uppsala University Hospital, Uppsala, Sweden 